\title{
O livro do conhecimento: uma aventura medieval pela aprendizagem de Gramática
}

\author{
Fernanda Gabriela S. Pires ${ }^{1,2}$, Fábio Michel ${ }^{1,2}$, João Ricardo Serique Bernardo ${ }^{1,2}$, \\ Rafaela Melo Ferreira ${ }^{1,2}$ \\ ${ }^{1}$ Licenciatura em Computação - Universidade do Estado do Amazonas (UEA) \\ Av. Darcy Vargas, 1.200- 69050-020 - Manaus - AM - Brazil \\ ${ }^{2}$ Laboratório de Tecnologias Educacionais - Universidade do Estado do Amazonas \\ Manaus, AM - Brazil \\ \{fmmdl.lic16,fpires,jrsbr.lic16,rmf.lic16\}@uea.edu.br
}

Resumo. O presente artigo traz o processo de desenvolvimento do software intitulado O Livro do Conhecimento. O jogo foi desenvolvido com o objetivo de auxiliar a aprendizagem da escrita correta de palavras da Língua Portuguesa e aplicações em frases. O software possui fundamentação na Teoria Cognitiva da Aprendizagem Multimídia, de Richard Mayer e, proporciona uma experiência simples e divertida, mas com o foco nos conteúdos referentes à ortografia.

\section{Cenário de Uso}

Aprender a língua materna é fundamental para qualquer indivíduo na aquisição de habilidades de comunicação (fala e escrita). Com a finalidade de se obter domínio da língua portuguesa, diversas metodologias vem sendo desenvolvidas com o objetivo de auxiliar os brasileiros nos processos de comunicação de forma adequada (Yamato, Corrêa et al. 2017).

Dados obtidos em avaliações indicam falta de domínio da língua portuguesa por parte dos brasileiros. Em 2016, na Avaliação Nacional de Alfabetização (ANA)3 4,46\% dos participantes da tiveram um rendimento inadequado já nas primeiras séries do Ensino Fundamental. Em 2016, dados dos ENEM mostraram que mais de 291.000 candidatos zeraram a nota em redação e que apenas 77 obtiveram a nota máxima. Tais números indicam as dificuldades de escrita e leitura que os brasileiros possuem (INEP 2017).

Diante desse cenário, diversos esforços têm sido realizados com o objetivo de promover meios que auxiliem a melhora dos índices da aprendizagem em língua portuguesa. Dentro disso está a produção de recursos midiáticos específicos que possam prover tal auxílio. Atualmente os jogos possuem grande impacto durante o processo de aprendizagem, pois, ao atrair os usuários, acaba proporcionando uma maior motivação nos estudos (Dichev and Dicheva 2017).

Este artigo apresenta o desenvolvimento de um jogo intitulado "O Livro do Conhecimento", criado com a finalidade de auxiliar na aprendizagem da escrita da língua portuguesa. O software tem como público alvo pessoas a partir dos 10 anos e está baseado nos princípios da Teoria Cognitiva da Aprendizagem Multimídia - reduzir o processamento estranho, gerenciamento do processamento essencial, promover $\mathrm{o}$ processamento generativo - de Richard Mayer (2003). A Teoria Cognitiva da Aprendizagem Multimídia de Richard Mayer visa a utilização de métodos que reduzam 
o processamento externo, de maneira a destacar o que é essencial em ambientes digitais que promovam a aprendizagem.

Durante seu desenvolvimento foram levados em consideração elementos cognitivos presentes no processamento da informação humana, fatores de IHC (Interação Humano Computador) bem como o processo de construção de aprendizagem em Língua Portuguesa. Nos fatores game play e storytelling, foram selecionados elementos que visam proporcionar uma experiência divertida e agradável. Possui uma mecânica de exploração, desafios, aventura e uma história imersiva, aliados aos requisitos cognitivos de aprendizagem.

\section{Desenvolvimento}

Nessa seção serão abordados aspectos técnicos referentes aos equipamentos e às especificações necessárias que estes devem conter, além das ferramentas utilizadas no desenvolvimento do software.

\subsection{Hardware}

- Windows 7 ou superior;

- Processador $1 \mathrm{Ghz0}$;

- Memória RAM mínima 2GB (Windows 7), Placa de Vídeo 128Mb;

- Mouse, teclado e som;

- Monitor com resolução $1024 \times 768$ com 32 bits de cores.

\subsection{Software}

Foram utilizadas as seguintes ferramentas:

- Adobe Photoshop CC 2017 (Edição de imagens);

- Adobe Illustrator CC 2017 (Edição de imagens);

- PowerPoint 2016 (Organização do game);

- Construct 2 (Programação do game).

\subsection{Engine}

A ferramenta escolhida para o desenvolvimento do software foi o Construct 2. A game engine possui qualidade, facilidade e bom desempenho durante a produção de jogos. Apesar de algumas limitações, pode-se destacar a qualidade final do software além e considerar que essa ferramenta não exige um hardware complexo. Além disso, o Construct 2 possui uma biblioteca aliada a um ambiente amigável que auxiliam no processo de desenvolvimento. Seu código fonte é baseado em HTML5, mas possui um sistema de programação visual através da definição de eventos e ações.

\subsection{Arte}

Neste capitulo é trabalhado os pontos artísticos do jogo, em questões de design, organização e aparência em geral.

\subsubsection{Resumo de estilo}

O jogo trabalha com cores frias em um perfil medieval, por serem utilizados personagens 
fictícios e toda uma temática envolvendo os pontos já citados, e principalmente focando na faixa etária do público a que o jogo se aplica, o estilo que melhor se encaixou nestes pontos foi o "Cartoon".

\subsubsection{Principais referências}

O software utiliza algumas características de jogos de referência como CupHead e Super Mario World. A principal referência nesses títulos é devido a sua mecânica simples, mas que proporcionam uma experiência divertida e uma história que motivam os jogadores a vencerem os desafios propostos.

\subsubsection{Personagens}

Os personagens são baseados em seres humanos e seres místicos, todos no estilo cartoon. O player principal é uma princesa guerreira, chamada Diana, esta é equipada por um arco e flecha, que será controlado pelo jogador para eliminação dos inimigos ao longo do jogo. Como inimigo principal, temos o elfo Valtor, que será controlado pelo computador, assim como os Trolls, Orcs e os demais inimigos secundários.

\section{Apresentação de software}

O livro do conhecimento é um jogo de plataforma, no estilo aventura e ação, em terceira pessoa, ambientado em um cenário medieval com Orcs, Trolls e Elfos com grandes poderes de destruição. Possui características de cenário e personagens no estilo "cartoon", com grande jogabilidade, permitindo movimentos sofisticados e realização de manobras especiais.

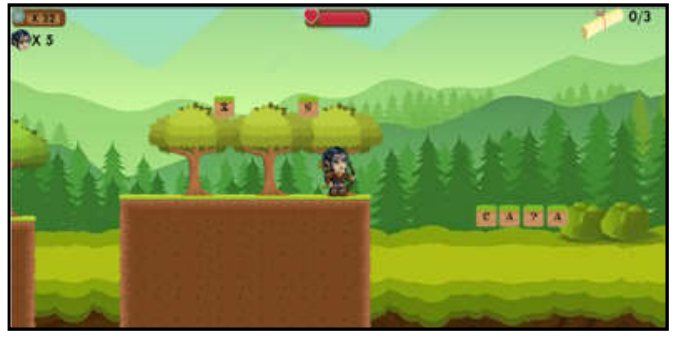

Figura 1. Desafios encontrados primeira fase

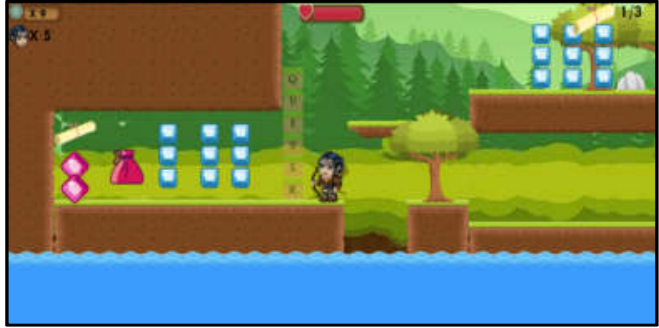

Figura 2. Objetos encontrados na na primeira fase

O jogo possui semelhanças com jogos já existentes como Cuphead, produzido pelos Studio MDHR, e Mario Word, produzido pela Nintendo. Seu diferencial é o enredo original, e, principalmente, o auxílio na aprendizagem de um conteúdo ortográfico de uma forma gamificada.

Visualmente atrativo e interativo, o game possui uma jogabilidade com movimentos e ações personalizados. Expondo o conteúdo da disciplina de português de forma lúdica, fazendo uma junção do conteúdo com objetos de cenário, passagens e perguntas pelo caminho de cada uma das fases, além de ser um jogo dinâmico e colorido, com animações trabalhadas com relação ao seu contexto, apresentadas durante a transição das fases, aproximando o jogador da história do jogo, revelando novas informações e fatos à medida que cada percurso é concluído, fazendo com que a expectativa em jogar seja ainda maior. 


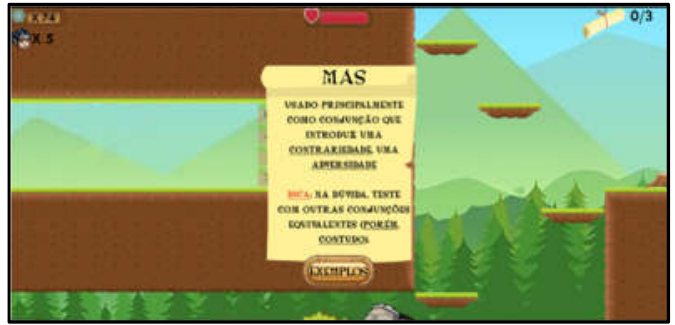

Figura 3. Página perdida do livro na primeira fase

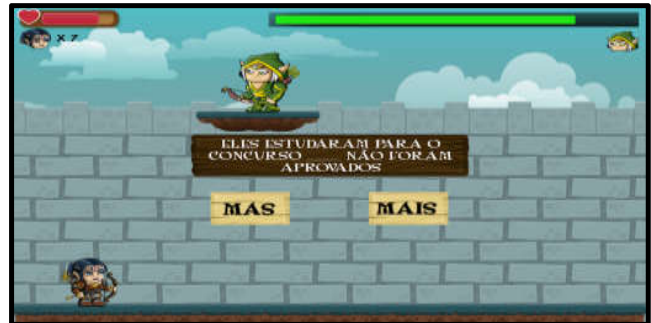

Figura 4. Luta contra o primeiro chefe

Tendo também personagens com características referentes ao tempo da história do jogo, cenários distintos a cada fase e possibilidade de aprendizagem, é ótimo para o desenvolvimento de reflexos e raciocínio rápido, além dos conhecimentos adquiridos sobre ortografia, pois exige uma rápida tomada de decisões em situações diferentes durante o percurso por cada fase.

\subsection{Personagem}

A personagem principal tem características humanas com estilo medieval. A figura 13 exibe a player representada por Diana, a mesma possui um arco e flecha que é controlado pelo jogador.

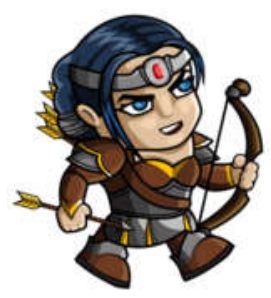

Figura 5. Personagem principal (Diana)

\subsection{Inimigos}

De acordo com o tema do jogo, o vilão Valtor e seu exército invadem Damaris, enfeitiçando e sequestrando seus moradores, criando armadilhas por todo lugar, no caso, inimigos que buscam proteger o novo Rei Naldo de Valtor. Considerando as características medievais do game, descritas em cenários (seção 3.3), serão utilizados diferentes tipos de inimigos por fase, como os a seguir:

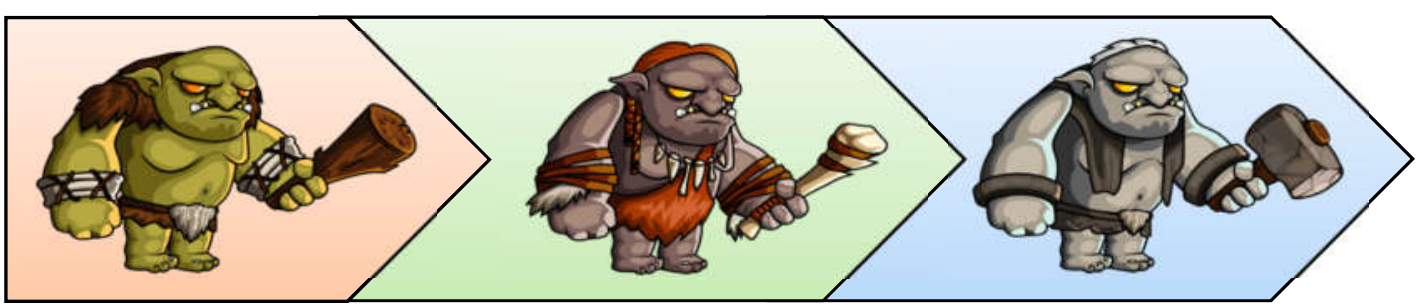

Figura 6. Trolls (Primeira e quarta fase)

\subsection{Cenários}


Cada um dos cenários é baseado nas características de cada fase do jogo. O cenário da primeira fase (Figura 8) representa uma floresta com árvores e montanhas enormes. Em cada parte da fase existe uma organização diferente de plataformas, inimigos e armadilhas.

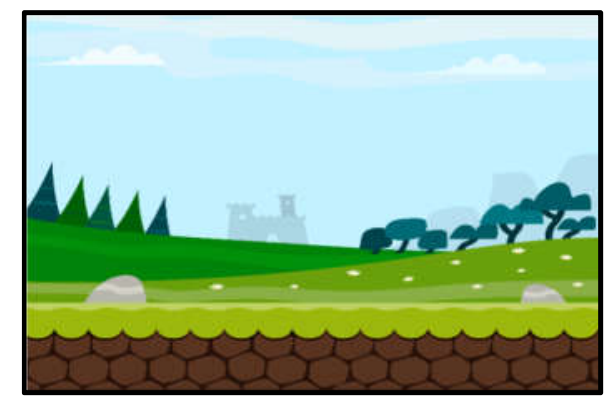

Figura 7. Cenário de menu principal

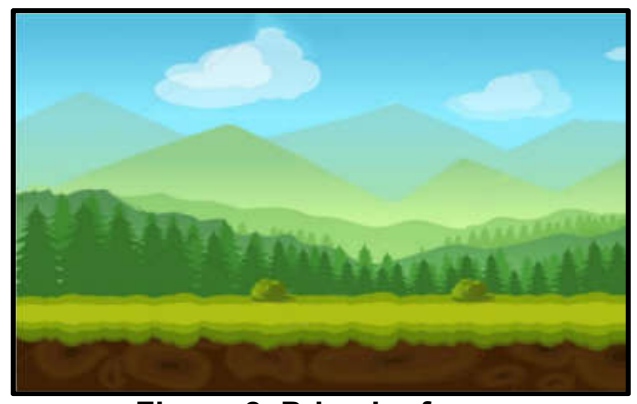

Figura 8. Primeira fase

\subsection{H.U.D. (Head Up Display)}

O HUD é composto pelos seguintes elementos:

- Barra de vida (demonstra o nível de vida, em questão de ataques de inimigos);

- Número de vidas: (indica o número de vidas que o player ainda possui);

- Papiros recolhidos: (demonstra a quantidade de papiros que o player adquiriu pela fase);

- Barra de moedas: (indica o número de joias que o player coletou).

$$
\begin{array}{r}
\times 17 \\
\times 18 \times 5 \\
\hline
\end{array}
$$

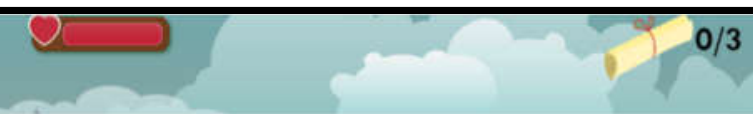

Figura 9. HUD do jogo

\section{Considerações finais}

Para que os jogadores tenham uma experiência de jogo adequada, a usabilidade é essencial. Se for mal elaborada, pode causar desinteresse (Cuperschmid and Hildebrand 2013). Por isso, O Livro do Conhecimento foi desenvolvido para que os jogadores desfrutem de um software divertido e que se sintam motivados para vencer os desafios.

Com o objetivo de avaliar o nível de diversão, imersão e prazer que o jogo proporciona, foi utilizado o método conhecido como Game Flow, que visa aplicar heurísticas quanto à usabilidade e experiência do jogador. As avaliações foram fundamentais para realizar alguns ajustes e melhorias no software. Além disso, os comentários dos avaliadores serviram de base para o desenvolvimento de uma versão móvel, adição de novas fases e uma segunda versão do game.

\section{Referências}

Cuperschmid, A. R. M. and H. R. Hildebrand (2013). Heurísticas de jogabilidade: usabilidade e entretenimento em jogos digitais, Marketing Aumentado.

Dichev, C. and D. Dicheva (2017). "Gamifying education: what is known, what is 
VII Congresso Brasileiro de Informática na Educação (CBIE 2018)

Anais dos Workshops do VII Congresso Brasileiro de Informática na Educação (WCBIE 2018)

believed and what remains uncertain: a critical review." International Journal of Educational Technology in Higher Education 14(1): 9.

INEP (2017). Censo Escolar da Educação Básica 2016: notas estatísticas, Instituto Nacional de Estudos e Pesquisas Educacionais Anísio Teixeira: 28.

Mayer, R. E. (2003). "The promise of multimedia learning: using the same instructional design methods across different media." Learning and instruction 13(2): 125-139.

Yamato, E. M., et al. (2017). AmarganA: A spelling game of the Portuguese language for use in mobile devices. Information Systems and Technologies (CISTI), 2017 12th Iberian Conference on, IEEE. 